\title{
An Evaluation of Students' Performance in Poster Presentations using Fuzzy Evaluation Method
}

\author{
Khairu Azlan Abd Aziz ${ }^{1 *}$, Mohd Fazril Izhar Mohd Idris², Wan Suhana Wan Daud ${ }^{3}$, \\ Muhamad Amirul Sudin ${ }^{4}$ \\ 1,2,4 Faculty of Computer and Mathematical Sciences, \\ Universiti Teknologi MARA, Perlis Branch, Arau Campus, 02600 Arau, Perlis, Malaysia \\ ${ }^{3}$ Institute of Engineering Mathematics, Universiti Malaysia Perlis, Arau 02600, Malaysia
}

Corresponding author:*khairu493@uitm.edu.my

Received Date: 8 August 2021

Accepted Date: 27 August 2021

Published Date: 13 September 2021

\section{HIGHLIGHTS}

- Fuzzy Evaluation Method is used as an alternative technique to measure the students' performance of poster presentation.

- The method consists of normalizing the marks, developing the graph of membership function, calculating the degree of satisfaction, and finalizing the marks.

- The samples of this study are from Mathematics and Computer final year students.

\begin{abstract}
Poster presentation encompasses many elements such as the organization of poster, the content related to the title proposed, the appearance and the written word. Usually, the poster presentation is used as a platform for student to present their final year project or any other competitions. Students will be evaluated based on the criteria that meets the requirements proposed by the panels or judges. However, their performance in poster presentations does not provide the suitable techniques to estimate the actual value since it involves the elements of fuzziness. In this study, the fuzzy evaluation technique will be applied to measure the performance of the poster presentation. The motivation behind poster presentation is to determine the performance of students using fuzzy evaluation method. The objective of this study is to compare the results between using conventional method and fuzzy evaluation method. The method consists of normalizing the marks, developing the graph of fuzzy membership function, calculating the degree of satisfaction, and finalizing the actual marks. We believed that the result from this study could be able to measure the better output with the consideration of linguistic terms includes excellent, good, moderate, satisfactory, and so on. This method also can be an alternative way to evaluate the performance of the poster presentation.
\end{abstract}

Keywords: poster presentation, fuzzy evaluation method, students' performance, membership function

\section{INTRODUCTION}

Posters are designed in a way for society to present the outcomes or demonstrate the evidence of content delivery using several approaches such as statistical evaluation, program evaluation, or mathematical model. For instance, final year students were used the poster presentations to show their findings which can 
be seen by the audience and evaluated by the panels. In other words, posters are useful in many sessions, discussions, and exhibitions as they attract the panels and audience to understand the content delivered. Primarily, the presentation must be systematized well in a proper language to keep the audience engaged so that they are interested to understand the content delivered. However, the technique to measure the performance of students in poster presentation need to be concerned. It is because an issue arises since the evaluation process involving the examiners or judges facing a difficulty to define the linguistic standards for each of marks. The selection of attributes to be assessed also important to evaluate the performance of students (Kharola et al. 2015). The elements of fuzziness in the assessment can make the judgement questionable.

In this study, the fuzzy evaluation method provides an alternative way on how poster presentations were assessed and more convenient to be applied compared to other artificial intelligence methods (Zaporozhko et al. 2020). The technique of fuzzy is developed in order to be more analytically and competence since the conventional method is lack of fuzziness elements. Thus, it can be more accurate to finalize the marks. Other than that, it provides an improved result or outcome since it delivers extra evidence of the student presentation for any kind of benchmarks. Moreover, the fuzzy evaluation method is able to manage the unclear systems and the use of language variables. The fuzzy evaluation method including standardizing the marks, acquiring the membership function of the graph, analyzing the degree of satisfaction, and calculating the final marks. The fuzzy evaluation method is a process of many-valued reasoning in which the truth-value may be interval number between 0 and 1 . Then, it is improved to carry out the hypothesis of fractional truth between true and false. By using Boolean logic, the truth-values of limit may be the interval between 0 and 1 . Datasets of 10 students were collected and selected for evaluation purpose as a sample of this study. The parameters for this study are the content delivery, appearance, poster organization and the written word in terms of language.

\section{METHODOLOGY}

\section{Normalizing the Marks}

The scores obtained by each of the student must be transferred to normalized value. Normalized value is described as a value in an interval of $[0,1]$ and it can be found by allocating the mark for each parameter with the total mark. Table 1 shows the example for calculating the normalized value by equation 1 .

Table 1: Example of normalized marks obtained by student

\begin{tabular}{|l|c|c|c|}
\hline \multicolumn{1}{|c|}{ Criteria } & Total marks & Mark obtained & The Normalized value \\
\hline Organization (C1) & 30 & 26.5 & 0.89 \\
\hline Content (C2) & 20 & 17 & 0.85 \\
\hline Appearance (C3) & 20 & 18 & 0.9 \\
\hline Written word (C4) & 30 & 24 & 0.8 \\
\hline
\end{tabular}

$$
\text { normalized value }(N V)=\frac{\text { marks obtained }(M O)}{\text { total marks }(T M)}
$$

where $(\mathrm{NV})=$ normalized value for each criterion, $(\mathrm{TM})=$ total marks and $(\mathrm{MO})=$ marks obtained

\section{Developing the Graph of Fuzzy Membership Function


The graph of membership function is established to display the fuzzification method. Hameed and Sorensen (2010) said that the input value of variables can be designed using graph of triangular membership function. Table 2 shows the standard satisfaction level and its corresponding degree of satisfaction used in this study (Daud et al.,2011). The objective of developing graph membership function is to find the suitable fuzzy membership value of the specific input value as shown in figure 1.

Table 2: Standard satisfaction level and the corresponding degree of satisfaction

\begin{tabular}{|l|c|c|}
\hline \multicolumn{1}{|c|}{ Satisfaction levels (X) } & Degree of Satisfaction & Maximum Degree of Satisfaction T(X) \\
\hline Exceptional (ET) & $80 \%-100 \%(0.8-1.0)$ & 1.0 \\
\hline Excellent (EX) & $75 \%-79 \%(0.75-0.79)$ & 0.79 \\
\hline Very Good (VG) & $70 \%-74 \%(0.7-0.74)$ & 0.74 \\
\hline Fairly Good (FG) & $65 \%-69 \%(0.65-0.69)$ & 0.69 \\
\hline Marginally Good (MG) & $60 \%-64 \%(0.6-0.64)$ & 0.64 \\
\hline Competent (CT) & $55 \%-59 \%(0.55-0.59)$ & 0.59 \\
\hline Fairly Competent (FC) & $50 \%-54 \%(0.5-0.54)$ & 0.54 \\
\hline Marginally Competent (MC) & $45 \%-49 \%(0.45-0.49)$ & 0.49 \\
\hline Bad (BD) & $40 \%-44 \%(0.4-0.44)$ & 0.44 \\
\hline Fairly Bad (FB) & $35 \%-39 \%(0.35-0.39)$ & 0.39 \\
\hline Marginally Bad (MB) & $30 \%-34 \%(0.3-0.34)$ & 0.34 \\
\hline Fail (F) & $0-29 \%(0-0.29)$ & 0.29 \\
\hline
\end{tabular}

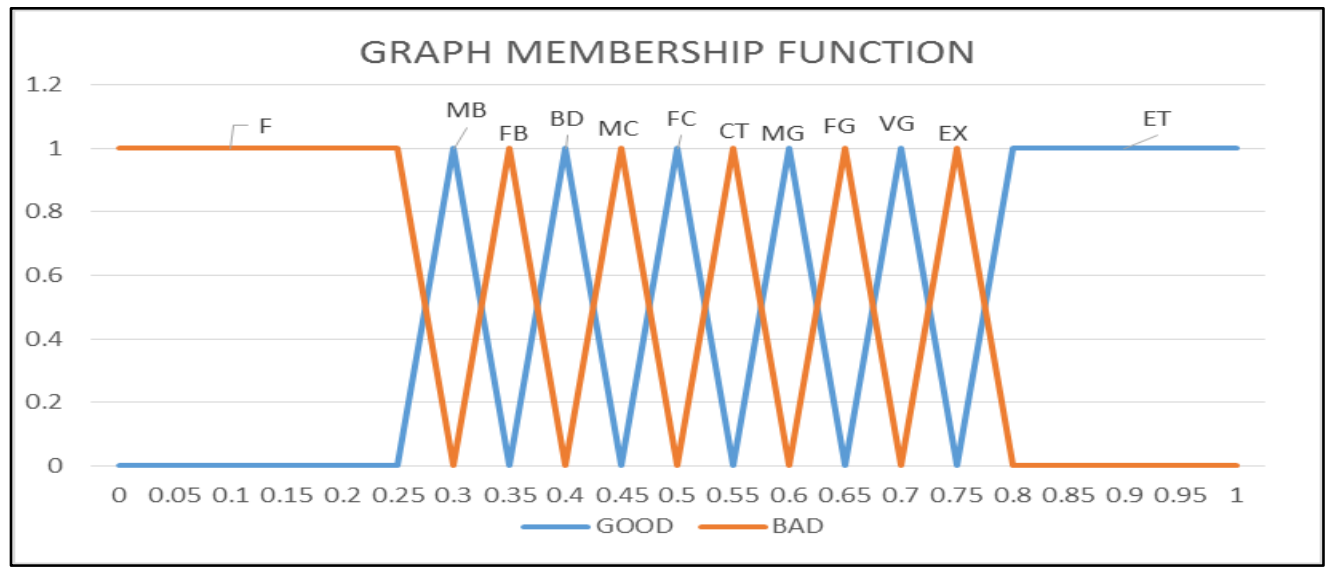

Figure 1: Example of graph membership function for satisfaction level

\section{Calculating the Degree of Satisfaction}

Degree of satisfaction marks was computed based on a graph of membership function. As the degree of satisfaction was placed, we can compute the values using following equation 2 :

$$
\text { Degree of satisfaction }=\frac{A_{1}\left(T x_{1}\right)+. A_{2}\left(T x_{2}\right) \ldots \ldots . . A_{12} T\left(x_{12}\right)}{A_{1}+A_{2}+\ldots \ldots A_{12}}
$$

where $A=$ degree of membership value and $T(X)=$ the maximum degree of satisfaction 


\section{Computing the Final Mark}

The final mark was calculated using the degree of satisfaction level and the equation is stated as follows:

$$
\text { Final mark }=\frac{B_{1} D\left(C_{1}\right)+B_{2} D\left(C_{2}\right)+B_{3} D\left(C_{3}\right)+B_{4} D\left(C_{4}\right)}{B_{1}+B_{2}+B_{3}+B_{4}}
$$

where $B=$ the total marks obtained and $D(C)=$ degree of satisfaction value for each criterion

\section{FINDINGS AND DISCUSSIONS}

\section{Data Collection and Evaluation}

Ten Mathematics and Computer students were selected for the samples of this study. There were four criteria to be included in evaluating the performance. These criteria were finalized by judges or examiners to provide the appropriate result as shown in table 3.

Table 3: Samples of poster evaluation marks obtained by students

\begin{tabular}{|l|c|c|c|c|c|c|c|c|c|c|c|}
\hline Criteria & Total Marks & S1 & S2 & S3 & S4 & S5 & S6 & S7 & S8 & S9 & S10 \\
\hline C1 & 30 & 26.5 & 26 & 25.5 & 27 & 24.5 & 24 & 23.5 & 23 & 22.5 & 20 \\
\hline C2 & 20 & 17 & 16.5 & 16 & 15.5 & 18 & 15 & 12 & 14.5 & 14 & 13.5 \\
\hline C3 & 20 & 18.5 & 17.5 & 17 & 13 & 16.5 & 16 & 18.5 & 15.5 & 15 & 14.5 \\
\hline C4 & 30 & 23.5 & 26.5 & 26 & 25.5 & 25 & 24 & 24 & 26.5 & 23.5 & 21.5 \\
\hline & & $\mathbf{8 5 . 5}$ & $\mathbf{8 6 . 5}$ & $\mathbf{8 4 . 5}$ & $\mathbf{8 1}$ & $\mathbf{8 4}$ & $\mathbf{7 9}$ & $\mathbf{7 8}$ & $\mathbf{7 9 . 5}$ & $\mathbf{7 5}$ & $\mathbf{6 9 . 5}$ \\
\hline
\end{tabular}

\section{Normalizing the Marks}

The scores obtained by each of the student must be transferred to standardized value. Normalizing value was defined as a value in an interval of $[0,1]$. It can be found by distributing the marks for each specification with the total marks. Table 4 depicts the calculation of normalizing students' marks using equation 1 .

Table 4: Calculation of Normalizing Students' Marks

\begin{tabular}{|l|c|c|c|c|c|c|c|c|c|c|}
\hline Criteria & S1 & S2 & S3 & S4 & S5 & S6 & S7 & S8 & S9 & S10 \\
\hline C1 & 0.88 & 0.87 & 0.85 & 0.9 & 0.82 & 0.8 & 0.78 & 0.77 & 0.75 & 0.67 \\
\hline C2 & 0.85 & 0.83 & 0.8 & 0.78 & 0.9 & 0.75 & 0.6 & 0.73 & 0.7 & 0.68 \\
\hline C3 & 0.93 & 0.88 & 0.85 & 0.65 & 0.83 & 0.8 & 0.93 & 0.78 & 0.75 & 0.73 \\
\hline C4 & 0.78 & 0.88 & 0.87 & 0.85 & 0.83 & 0.8 & 0.8 & 0.88 & 0.78 & 0.72 \\
\hline
\end{tabular}

\section{Plotting the Graph of Fuzzy Membership Function and Calculating the Degree of Satisfaction}

The graph of membership function is established to display the fuzziness values. In this process, the input value for any variables is plotted in the graph of triangular membership function with the mode, left 
endpoint, and right endpoint. Cheng (2004) said triangular fuzzy number is widely used in both research and practice. Since the degree of satisfaction was ranked, then the evaluation of the poster has been performed. Table 5 shows the calculation of the degree satisfaction for each criterion in poster presentation.

Table 5: Calculation of the degree satisfaction for any criteria

\begin{tabular}{|c|c|c|c|c|c|c|c|c|c|c|c|c|c|c|}
\hline \multirow[t]{2}{*}{ St } & \multirow[t]{2}{*}{$\mathrm{C}$} & \multicolumn{12}{|c|}{ Fuzzy Membership Value } & \multirow[t]{2}{*}{$\mathrm{D}$} \\
\hline & & $\mathrm{F}$ & MB & FB & $\mathrm{BD}$ & $\mathrm{MC}$ & FC & CT & MG & FG & VG & $\mathrm{EX}$ & ET & \\
\hline \multirow[t]{4}{*}{1} & $\mathrm{C} 1$ & 0 & 0 & 0 & 0 & 0 & 0 & 0 & 0 & 0 & 0 & 0.12 & 0.88 & 0.975 \\
\hline & $\mathrm{C} 2$ & 0 & 0 & 0 & 0 & 0 & 0 & 0 & 0 & 0 & 0 & 0.15 & 0.85 & 0.969 \\
\hline & $\mathrm{C} 3$ & 0 & 0 & 0 & 0 & 0 & 0 & 0 & 0 & 0 & 0 & 0.07 & 0.93 & 0.985 \\
\hline & $\mathrm{C} 4$ & 0 & 0 & 0 & 0 & 0 & 0 & 0 & 0 & 0 & 0.22 & 0.78 & 0 & 0.779 \\
\hline \multirow[t]{4}{*}{2} & $\mathrm{C} 1$ & 0 & 0 & 0 & 0 & 0 & 0 & 0 & 0 & 0 & 0 & 0.18 & 0.82 & 0.962 \\
\hline & $\mathrm{C} 2$ & 0 & 0 & 0 & 0 & 0 & 0 & 0 & 0 & 0 & 0 & 0.17 & 0.83 & 0.964 \\
\hline & C3 & 0 & 0 & 0 & 0 & 0 & 0 & 0 & 0 & 0 & 0 & 0.15 & 0.85 & 0.969 \\
\hline & $\mathrm{C} 4$ & 0 & 0 & 0 & 0 & 0 & 0 & 0 & 0 & 0 & 0 & 0.17 & 0.83 & 0.964 \\
\hline \multirow[t]{4}{*}{3} & $\mathrm{C} 1$ & 0 & 0 & 0 & 0 & 0 & 0 & 0 & 0 & 0 & 0 & 0.15 & 0.85 & 0.969 \\
\hline & $\mathrm{C} 2$ & 0 & 0 & 0 & 0 & 0 & 0 & 0 & 0 & 0 & 0 & 0.8 & 0.2 & 0.832 \\
\hline & C3 & 0 & 0 & 0 & 0 & 0 & 0 & 0 & 0 & 0 & 0 & 0.16 & 0.84 & 0.966 \\
\hline & $\mathrm{C} 4$ & 0 & 0 & 0 & 0 & 0 & 0 & 0 & 0 & 0 & 0 & 0.13 & 0.87 & 0.973 \\
\hline \multirow[t]{4}{*}{4} & $\mathrm{C} 1$ & 0 & 0 & 0 & 0 & 0 & 0 & 0 & 0 & 0 & 0 & 0.9 & 0.1 & 0.979 \\
\hline & $\mathrm{C} 2$ & 0 & 0 & 0 & 0 & 0 & 0 & 0 & 0 & 0 & 0.22 & 0.78 & 0 & 0.779 \\
\hline & C3 & 0 & 0 & 0 & 0 & 0 & 0 & 0 & 0.35 & 0.65 & 0 & 0 & 0 & 0.673 \\
\hline & $\mathrm{C} 4$ & 0 & 0 & 0 & 0 & 0 & 0 & 0 & 0 & 0 & 0 & 0.15 & 0.85 & 0.969 \\
\hline \multirow[t]{4}{*}{5} & $\mathrm{C} 1$ & 0 & 0 & 0 & 0 & 0 & 0 & 0 & 0 & 0 & 0 & 0.22 & 0.78 & 0.954 \\
\hline & $\mathrm{C} 2$ & 0 & 0 & 0 & 0 & 0 & 0 & 0 & 0 & 0 & 0 & 0.05 & 0.95 & 0.99 \\
\hline & C3 & 0 & 0 & 0 & 0 & 0 & 0 & 0 & 0 & 0 & 0 & 0.18 & 0.82 & 0.962 \\
\hline & $\mathrm{C} 4$ & 0 & 0 & 0 & 0 & 0 & 0 & 0 & 0 & 0 & 0 & 0.19 & 0.81 & 0.96 \\
\hline \multirow[t]{4}{*}{6} & $\mathrm{C} 1$ & 0 & 0 & 0 & 0 & 0 & 0 & 0 & 0 & 0 & 0 & 0.81 & 0.19 & 0.83 \\
\hline & $\mathrm{C} 2$ & 0 & 0 & 0 & 0 & 0 & 0 & 0 & 0 & 0 & 0.25 & 0.75 & 0 & 0.778 \\
\hline & C3 & 0 & 0 & 0 & 0 & 0 & 0 & 0 & 0 & 0 & 0 & 0.82 & 0.18 & 0.828 \\
\hline & $\mathrm{C} 4$ & 0 & 0 & 0 & 0 & 0 & 0 & 0 & 0 & 0 & 0 & 0.18 & 0.82 & 0.962 \\
\hline \multirow[t]{4}{*}{7} & $\mathrm{C} 1$ & 0 & 0 & 0 & 0 & 0 & 0 & 0 & 0 & 0 & 0.22 & 0.78 & 0 & 0.779 \\
\hline & $\mathrm{C} 2$ & 0 & 0 & 0 & 0 & 0 & 0 & 0.4 & 0.6 & 0 & 0 & 0 & 0 & 0.62 \\
\hline & C3 & 0 & 0 & 0 & 0 & 0 & 0 & 0 & 0 & 0 & 0 & 0.12 & 0.88 & 0.975 \\
\hline & $\mathrm{C} 4$ & 0 & 0 & 0 & 0 & 0 & 0 & 0 & 0 & 0 & 0 & 0.81 & 0.19 & 0.83 \\
\hline \multirow[t]{4}{*}{8} & $\mathrm{C} 1$ & 0 & 0 & 0 & 0 & 0 & 0 & 0 & 0 & 0 & 0.23 & 0.77 & 0 & 0.779 \\
\hline & $\mathrm{C} 2$ & 0 & 0 & 0 & 0 & 0 & 0 & 0 & 0 & 0.27 & 0.73 & 0 & 0 & 0.727 \\
\hline & C3 & 0 & 0 & 0 & 0 & 0 & 0 & 0 & 0 & 0 & 0.22 & 0.78 & 0 & 0.779 \\
\hline & $\mathrm{C} 4$ & 0 & 0 & 0 & 0 & 0 & 0 & 0 & 0 & 0 & 0 & 0.15 & 0.85 & 0.969 \\
\hline \multirow[t]{4}{*}{9} & $\mathrm{C} 1$ & 0 & 0 & 0 & 0 & 0 & 0 & 0 & 0 & 0 & 0.25 & 0.75 & 0 & 0.778 \\
\hline & $\mathrm{C} 2$ & 0 & 0 & 0 & 0 & 0 & 0 & 0 & 0 & 0.3 & 0.7 & 0 & 0 & 0.725 \\
\hline & C3 & 0 & 0 & 0 & 0 & 0 & 0 & 0 & 0 & 0 & 0.26 & 0.74 & 0 & 0.777 \\
\hline & $\mathrm{C} 4$ & 0 & 0 & 0 & 0 & 0 & 0 & 0 & 0 & 0 & 0.22 & 0.78 & 0 & 0.779 \\
\hline 10 & $\mathrm{C} 1$ & 0 & 0 & 0 & 0 & 0 & 0 & 0 & 0.33 & 0.67 & 0 & 0 & 0 & 0.674 \\
\hline
\end{tabular}




\begin{tabular}{|c|c|c|c|c|c|c|c|c|c|c|c|c|c|c|}
\hline & $\mathrm{C} 2$ & 0 & 0 & 0 & 0 & 0 & 0 & 0 & 0.29 & 0.71 & 0 & 0 & 0 & $\mathbf{0 . 6 7 6}$ \\
\cline { 2 - 13 } & $\mathrm{C} 3$ & 0 & 0 & 0 & 0 & 0 & 0 & 0 & 0 & 0.27 & 0.73 & 0 & 0 & $\mathbf{0 . 7 2 7}$ \\
\cline { 2 - 13 } & $\mathrm{C} 4$ & 0 & 0 & 0 & 0 & 0 & 0 & 0 & 0 & 0.26 & 0.74 & 0 & 0 & $\mathbf{0 . 7 2 7}$ \\
\hline
\end{tabular}

\section{Finalizing the Marks}

The panels or judges finalized the actual scores for each parameter. The final mark is computed using the equation 3. Table 6 shows the finalized marks obtained using fuzzy evaluation method.

Table 6: Finalizing the overall students' marks using fuzzy method

\begin{tabular}{|c|c|c|c|c|c|}
\hline Student & Criteria & Degree of satisfaction & Total marks & Final mark for criteria & Finalized marks \\
\hline \multirow[t]{4}{*}{1} & $\mathrm{C} 1$ & 0.975 & 30 & 29.25 & \multirow[t]{4}{*}{91.70} \\
\hline & $\mathrm{C} 2$ & 0.969 & 20 & 19.38 & \\
\hline & $\mathrm{C} 3$ & 0.985 & 20 & 19.7 & \\
\hline & $\mathrm{C} 4$ & 0.779 & 30 & 23.37 & \\
\hline \multirow[t]{4}{*}{2} & $\mathrm{C} 1$ & 0.962 & 30 & 28.86 & \multirow[t]{4}{*}{96.44} \\
\hline & $\mathrm{C} 2$ & 0.964 & 20 & 19.28 & \\
\hline & $\mathrm{C} 3$ & 0.969 & 20 & 19.38 & \\
\hline & $\mathrm{C} 4$ & 0.964 & 30 & 28.92 & \\
\hline \multirow[t]{4}{*}{3} & $\mathrm{C} 1$ & 0.969 & 30 & 29.07 & \multirow[t]{4}{*}{94.22} \\
\hline & $\mathrm{C} 2$ & 0.832 & 20 & 16.64 & \\
\hline & $\mathrm{C} 3$ & 0.966 & 20 & 19.32 & \\
\hline & $\mathrm{C} 4$ & 0.973 & 30 & 29.19 & \\
\hline \multirow[t]{4}{*}{4} & $\mathrm{C} 1$ & 0.979 & 30 & 29.37 & \multirow[t]{4}{*}{87.48} \\
\hline & $\mathrm{C} 2$ & 0.779 & 20 & 15.58 & \\
\hline & $\mathrm{C} 3$ & 0.673 & 20 & 13.46 & \\
\hline & $\mathrm{C} 4$ & 0.969 & 30 & 29.07 & \\
\hline \multirow[t]{4}{*}{5} & $\mathrm{C} 1$ & 0.954 & 30 & 28.62 & \multirow[t]{4}{*}{96.46} \\
\hline & $\mathrm{C} 2$ & 0.99 & 20 & 19.8 & \\
\hline & $\mathrm{C} 3$ & 0.962 & 20 & 19.24 & \\
\hline & $\mathrm{C} 4$ & 0.96 & 30 & 28.8 & \\
\hline \multirow[t]{4}{*}{6} & C1 & 0.83 & 30 & 24.9 & \multirow[t]{4}{*}{85.88} \\
\hline & $\mathrm{C} 2$ & 0.778 & 20 & 15.56 & \\
\hline & C3 & 0.828 & 20 & 16.56 & \\
\hline & $\mathrm{C} 4$ & 0.962 & 30 & 28.86 & \\
\hline \multirow[t]{4}{*}{7} & $\mathrm{C} 1$ & 0.779 & 30 & 23.37 & \multirow[t]{4}{*}{80.17} \\
\hline & $\mathrm{C} 2$ & 0.62 & 20 & 12.4 & \\
\hline & $\mathrm{C} 3$ & 0.975 & 20 & 19.5 & \\
\hline & $\mathrm{C} 4$ & 0.832 & 30 & 24.9 & \\
\hline \multirow[t]{4}{*}{8} & C1 & 0.779 & 30 & 23.37 & \multirow[t]{4}{*}{82.56} \\
\hline & $\mathrm{C} 2$ & 0.727 & 20 & 14.54 & \\
\hline & $\mathrm{C} 3$ & 0.779 & 20 & 15.58 & \\
\hline & $\mathrm{C} 4$ & 0.969 & 30 & 29.07 & \\
\hline \multirow[t]{4}{*}{9} & $\mathrm{C} 1$ & 0.778 & 30 & 23.34 & \multirow[t]{4}{*}{76.75} \\
\hline & $\mathrm{C} 2$ & 0.725 & 20 & 14.5 & \\
\hline & $\mathrm{C} 3$ & 0.777 & 20 & 15.54 & \\
\hline & $\mathrm{C} 4$ & 0.779 & 30 & 23.37 & \\
\hline \multirow[t]{4}{*}{10} & C1 & 0.674 & 30 & 20.22 & \multirow[t]{4}{*}{70.09} \\
\hline & $\mathrm{C} 2$ & 0.676 & 20 & 13.52 & \\
\hline & C3 & 0.727 & 20 & 14.54 & \\
\hline & $\mathrm{C} 4$ & 0.727 & 30 & 21.81 & \\
\hline
\end{tabular}

Table 7 shows the comparison between fuzzy evaluation method and conventional method with different satisfaction level. Evaluation technique using conventional methods expose to vagueness, uncertainty, and imprecision interpretation (Mamatha et al. 2016). While a different mark contributes to a different grade, 
Ivanova and Zlatanov (2020) said that the fuzzy model can be used to improve the problem of borderline grade.

Fuzzy evaluation method plays a significant role in determining the students' performance because it is an alternative tool when dealing with uncertainty decisions (Lin et al. 2006). The students' performance is denoted in the form of scores and linguistic terms, which involve elements of uncertainty. The evaluation process was inclusive with the aid of the membership function graph and the fuzzy grade sheet which was introduced by Chen and Lee (1999). Based on the evaluation, it can improve some additional information on the students' performance for each criterion. Besides that, the use of linguistic terms seems to be more beneficial so that the students can work harder to obtain the best level of performance for their future poster presentations. Hence, this approach can be applied as an alternative method in evaluating the students' performance in the poster presentations that may provide an improvement for upcoming event.

Table 7: The results obtained from both methods for 10 students

\begin{tabular}{|c|c|c|c|c|c|c|}
\hline \multirow[t]{2}{*}{ Student } & \multicolumn{3}{|c|}{ Conventional Method } & \multicolumn{3}{|c|}{ Fuzzy Method } \\
\hline & Final marks & Grade & Linguistic terms & Final marks & Grade & Linguistic terms \\
\hline 1 & 85 & A & Exceptional & 91.70 & $\mathrm{~A}+$ & Excellent at 0.07 and exceptional at 0.93 \\
\hline 2 & 86.5 & $\mathrm{~A}$ & Exceptional & 96.44 & $\mathrm{~A}+$ & Excellent at 0.18 and exceptional at 0.82 \\
\hline 3 & 84.5 & A & Exceptional & 94.22 & $\mathrm{~A}+$ & Excellent at 0.8 and exceptional at 0.2 \\
\hline 4 & 81 & A & Exceptional & 87.48 & $\mathrm{~A}$ & Excellent at 0.1 and exceptional at 0.9 \\
\hline 5 & 84 & A & Exceptional & 96.46 & $\mathrm{~A}+$ & Excellent at 0.22 and exceptional at 0.78 \\
\hline 6 & 79 & A- & Excellent & 85.88 & A & Excellent at 0.82 and exceptional at 0.18 \\
\hline 7 & 78 & A- & Excellent & 80.17 & A & Excellent at 0.12 and exceptional at 0.88 \\
\hline 8 & 79.5 & A- & Excellent & 82.56 & $\mathrm{~A}$ & Excellent at 0.15 and exceptional at 0.85 \\
\hline 9 & 75 & A- & Excellent & 76.75 & A- & Very good at 0.22 and excellent at 0.78 \\
\hline 10 & 69.5 & $\mathrm{~B}$ & Fairly good & 70.09 & $\mathrm{~B}+$ & Fairly good at 0.27 and very good at 0.73 \\
\hline
\end{tabular}

\section{CONCLUSION AND RECOMMENDATIONS}

Fuzzy evaluation method plays an important part since the information based design rules can effortlessly be executed in frameworks with unknown structure. The control design methodology is straightforward and common sense based on linguistic information. Other than that, fuzzy evaluation method is suitable for evaluating the students' performance in any education such as poster performance, video presentation and oral presentation. A multi criteria examination in positioning the students' performance using fuzzy evaluation is proposed. The proposed method uses the application of fuzzy sets and approximate reasoning in choosing the positioning of the quality of educating in a few courses. In other words, it also introduces the normalized value for evaluating the marks which dampen the extraordinary esteem that exists in the information. The use of the model is reasonable in evaluating situations that involve subjectivity, vagueness and imprecise information. Experimental results are comparable and the method used are performed way better in few decisions.

Other than that, fuzzy evaluation method uncovers that significant amount of work has been carried out to recognize the students' performance and further exploration of both the theoretical and empirical literature review. Therefore, conventional method sometimes is inappropriate and incompetent in some cases. However, fuzzy evaluation method is a very powerful tool to compensate this limitation and deal with vague and complex situations. This clearly uncovers that there is an urgent need for an alternative method for 
evaluating the students' performance in poster presentation using fuzzy evaluation method. Therefore, it seems clear that there is an urgent need for the implementation of students' performance in poster presentation which investigates the other qualitative factors that are responsive and reliable

\section{REFERENCES}

Chen, S.M. \& Lee, C.H. (1999). New methods for students' evaluation. Fuzzy Sets and Systems, vol. 104, pp. 209-218.

Cheng, C.B. (2004). Group opinion aggregation based on a grading process: A method for constructing triangular fuzzy numbers. Computers and Mathematics with Applications, vol. 48, pp. 1619-1632.

Daud, W.S.W., Abd Aziz, K.A. \& Sakib, E. (2011). An Evaluation of Students' Performance in Oral Presentation Using Fuzzy Approach. Empowering Science, Technology and Innovation towards a Better Tomorrow, UMTAS, pp. 157-162.

Hameed, I.A. \& Sorensen C.G. (2010) Fuzzy systems in education: A more reliable system for student evaluation. In: Fuzzy Systems. InTech, Croatia, pp 1-16.

Ivanova, V. \& Zlatanov, B. (2020). A note on the use of fuzzy logic in the evaluation of students' test results. MATTEX Conference 2020: Mathematics and Natural Sciences, vol. 1, pp. 21 - 25.

Kharola, A., Kunwar, S. \& Choudhury, G.B. (2015). Students' performance evaluation: A fuzzy logic reasoning approach. PM World Journal vol. IV, issue IX.

Lin, C.T, Chiu, H. \& Tseng, Y. H. (2006). Agility evaluation using fuzzy logic. International Journal of Production Economics, vol. 101, 2, pp. 353-368.

Mamatha, G., Sridhar R. \& Balasubramanian, S. (2016). Fuzzy logic as a tool for evaluation of performance appraisal of faculty in higher education institutions. SHS Web of Conference vol. 26, 01121.

Zaporozhko,V., Shardakov, V. \& Parfenov, D. (2020). Fuzzy model for evaluating the results of online learning. IOP Conference Series: Materials Science and Engineering 734012150. 